\title{
EFFECT OF SKEW ANGLE ON UPLIFT AND DEFLECTION OF RCC
}

\section{SKEW SLAB}

\author{
Deepak C' $\mathrm{C}^{1}$, Sabeena $\mathrm{MV}^{2}$ \\ ${ }^{1}$ MTech Student, Department of Civil Engineering, AWH Engineering College, Kerala, India \\ ${ }^{2}$ Professor and Head, Department of Civil Engineering, AWH Engineering College, Kerala, India
}

\begin{abstract}
The study deals with the finite element modeling of simply supported skew slab with varying skew angles using ANSYS software. The behavior of the simply supported skew slab under point load applied at the centre depends on the ratio of short diagonal to its span. Skew slabs with ratio of short diagonal to span less than unity show lifting of acute corners whereas slabs with ratio of short diagonal to span greater than unity do not. Skew slab specimen with ratio of short diagonal to span less than unity is considered here for studying the effect of skew angle on the behavior of skew slab. The dimensions of skew slab were taken from available experimental data. In this paper skew angles varying from $0^{\circ}$ to $30^{\circ}$ were taken for the study. After the nonlinear finite element analysis of all skew slabs it is revealed that when skew angle increases the uplift at both the acute corners also increases. The result also suggests that the load carrying capacity increases with increase in skew angle.
\end{abstract}

Keywords: Reinforced concrete, Finite element analysis, Skew slab, Uplift $* * *$

\section{INTRODUCTION}

Reinforced concrete skew slabs are widely used in bridge construction when the roads cross the streams and canals at angles other than 90 degrees. They are also used in floor system of reinforced concrete building as well as load bearing brick buildings where the floors and roofs are skewed for architectural reasons or space limitations. Skew slab bridges may be required to maintain the geometry of the road or keep the road straight at crossing or for any other reason.

To model the complex behavior of reinforced concrete analytically in its nonlinear zone is difficult. This has led engineers in the past to rely heavily on empirical formulas which were derived from numerous experiments for the design of reinforced concrete structures. The Finite Element Method (FEM) is an analytical tool which is able to model RCC structure and is able to calculate the nonlinear behavior of the structural members. For structural design and assessment of reinforced concrete members, the nonlinear finite element analysis has become an important tool. The method can be used to study the behavior of reinforced and pre-stressed concrete structures including both force and stress redistribution.

In the present work finite element modeling of RCC skew slab has been done in ANSYS. The behavior of the simply supported skew slab under point load applied at the centre depends on the ratio of short diagonal to its span. Skew slabs with ratio of short diagonal to span less than unity show lifting of acute corners whereas slabs with ratio of short diagonal to span greater than unity do not. This is because the reactions act at the obtuse corner only when the ratio of short diagonal to its span less than unity and it is well within supports when ratio of short diagonal to span is greater than unity [6]. So skew slabs with ratio of short diagonal to span less than unity is used here for studying the effect of skew angle on the uplift and deflection of skew slabs.

\section{GENERAL DESCRIPTION OF STRUCTURES}

Here, the modeling of skew slabs is based on experimental data obtained from the study on Flexural behavior of reinforced concrete skew slabs by Sharma B.R. [6]. In this study two skew slab specimens were considered. Specimen 1 having ratio of short diagonal to span less than unity and Specimen 2 having ratio of short diagonal to span greater than unity. The dimensions of Specimen 1 are used in this study. Skew slab Specimen 1 has been modeled with skew angle of $16.49^{\circ}$, the support length and span is kept as 1200 $\mathrm{mm}$ and $2470 \mathrm{~mm}$ respectively with M25 grade concrete. Thickness of slab has been kept as $70 \mathrm{~mm}$. Length of short diagonal of the slab is $2420 \mathrm{~mm}$ which is less than span $2470 \mathrm{~mm}$. Fig -1 shows the dimensions of specimen 1. Slab has been reinforced with main reinforcement of $8 \mathrm{~mm}$ diameter for steel bars @ $100 \mathrm{~mm} \mathrm{c} / \mathrm{c}$ at the bottom face of the slab at right angles to the supports and distribution reinforcement of also $8 \mathrm{~mm}$ diameter tor steel bars @ 125 $\mathrm{mm} \mathrm{c/c}$ laid over main reinforcement, parallel to the supports [6]. 


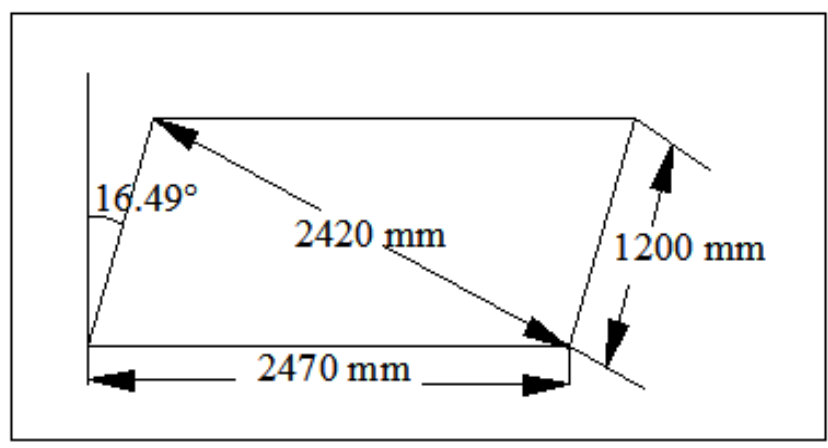

Fig -1: Dimensions of Experimental Test Specimen 1 [6]

In addition to $16.49^{\circ}$ skew angle, $0^{\circ}, 20^{\circ}$ and $30^{\circ}$ are also considered here for studying the effect of skew angle on the uplift and deflection of skew slab.

\section{FINITE ELEMENT MODELLING}

ANSYS, commercially available Finite Element (FE) software, of version 12.1 was used for the analysis of skew slabs. Concrete generally exhibits large number of micro cracks, especially, at the interface between coarse aggregates and mortar, even before it is subjected to any load. The presence of these micro cracks has a great effect on the mechanical behavior of concrete, since their propagation during loading contributes to the nonlinear behavior at low stress levels and causes volume expansion near failure. Some micro cracks may develop during loading because of the difference in stiffness between aggregates and mortar. Since the aggregate-mortar interface has a significantly lower tensile strength than mortar, it constitutes the weakest link in the composite system. This is the primary reason for the low tensile strength of concrete. The response of a structure under load depends largely on the stress-strain relation of the constituent materials and the magnitude of stress. The stress-strain relation in compression is of primary interest because mostly for compression members are cast using concrete. The actual behavior of concrete should be simulated using the chosen element type. For the present type of model solid65 and Link 8 elements were chosen. The Solid65 element was used to model the concrete. The solid element has eight nodes with three degrees of freedom at each nodetranslation in the nodal $\mathrm{x}, \mathrm{y}$ and $\mathrm{z}$ directions. The element is capable of plastic deformation, cracking in three orthogonal directions, and crushing. The geometry and node location for this element type are shown in Fig -2 .

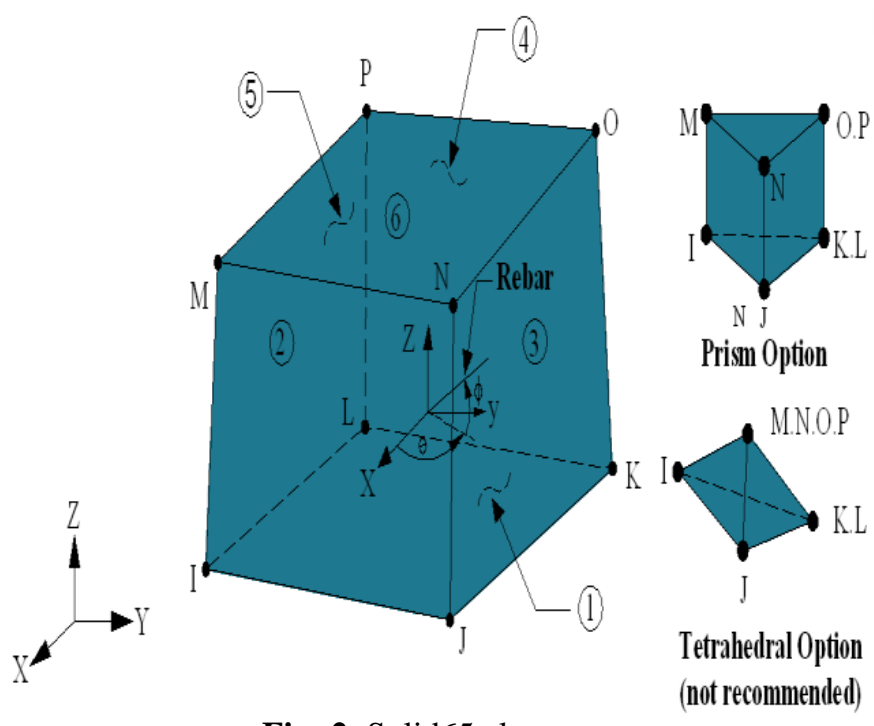

Fig -2: Solid65 element

A Link 8 was used to model the steel reinforcement. Two nodes are required for this element. Each node has three degrees of freedom at each node-translation in three nodal $x$, $\mathrm{y}$ and $\mathrm{z}$ directions as shown in Fig -3. The element is also capable of plastic deformation.
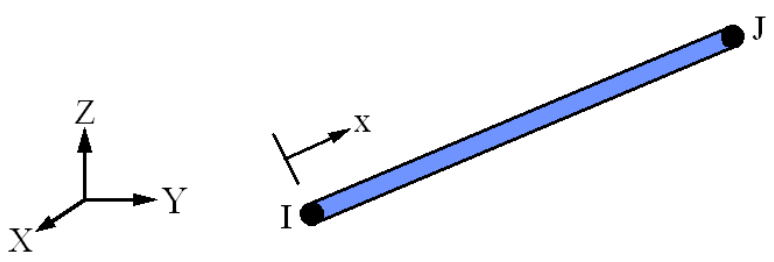

Fig -3: Link 8 element

\subsection{Nonlinear Analysis}

In nonlinear analysis, the total load applied to a finite element model is divided into a series of load increments called load steps. At the completion of each incremental solution, the stiffness matrix of the model is adjusted to reflect nonlinear changes in structural stiffness before proceeding to the next load increment.

The usefulness of the finite element method for nonlinear analysis very much depends on various numerical parameters which influence the solution. Different methods are available in ANSYS for solving non-linear equations such as, linear method, Full Newton-Raphson Method, Modified Newton-Raphson method etc. Among these the Full Newton-Raphson Method and Modified NewtonRaphson Method are more commonly used methods. In our present study, Full Newton-Raphson method is used for solving the simultaneous equations. It is an iterative process of solving the non-linear equations. 
Skew slabs having skew angle $0^{\circ}, 16.49^{\circ}, 20^{\circ}$ and $30^{\circ}$ are modeled in ANSYS and are presented in Fig -4, Fig -5, Fig -6 and Fig -7 respectively.

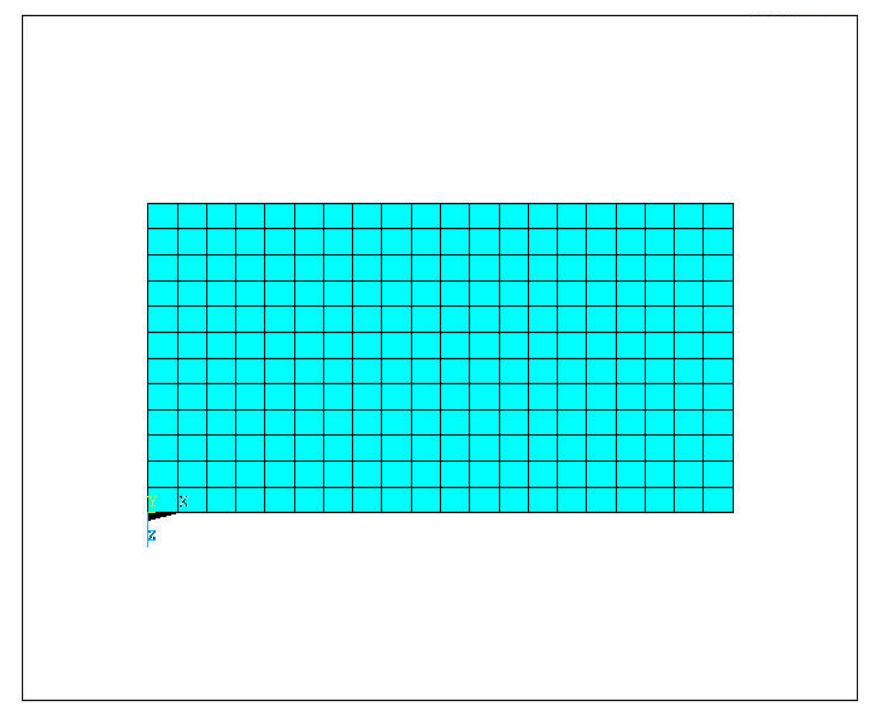

Fig -4: FE Model of Skew slab with $0^{\circ}$ skew

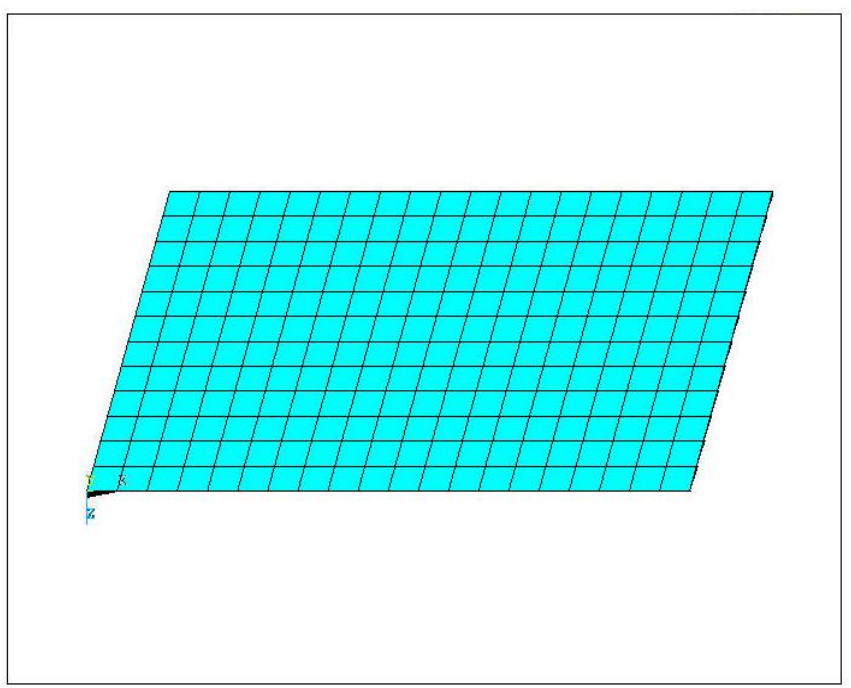

Fig -5: FE Model of Skew slab with $16.49^{\circ}$ skew

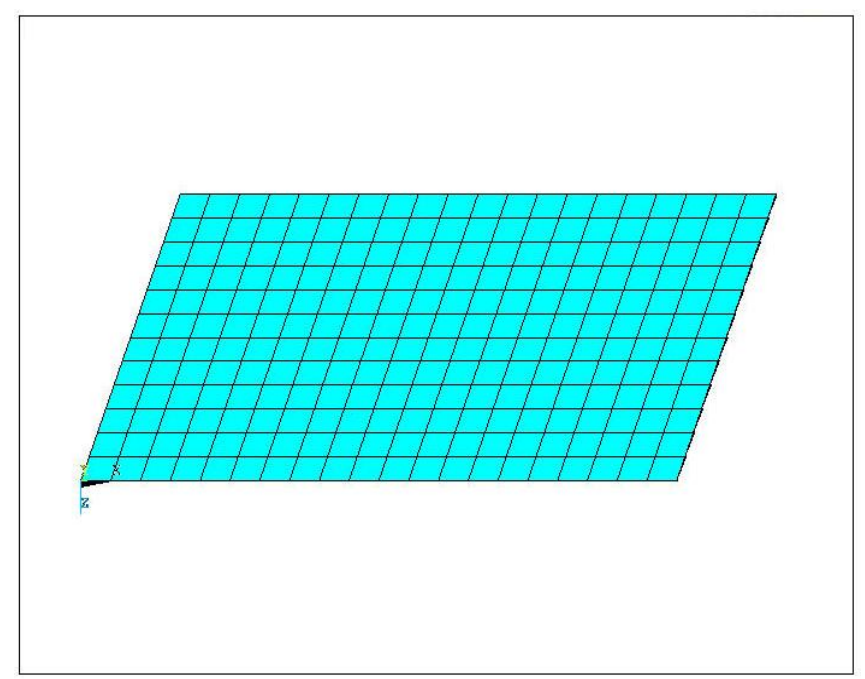

Fig -6: FE Model of Skew slab with $20^{\circ}$ skew

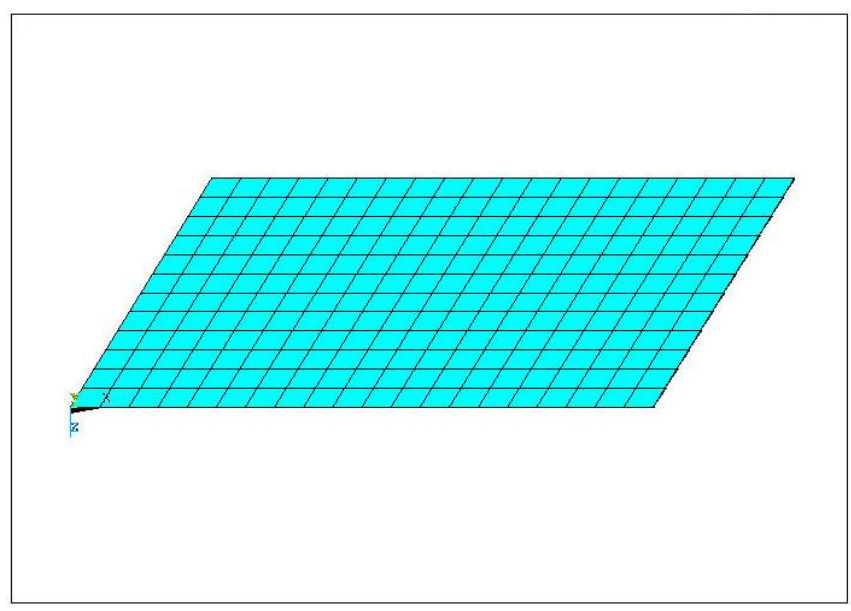

Fig -7: FE Model of Skew slab with $30^{\circ}$ skew

\section{RESULTS AND DISCUSSIONS}

In FE Model skew slab specimens loads have been applied at the centre of the slabs as done in case of experiment. The load on the structure has been gradually increased in the steps till failure. When the FE non linear analysis is completed, the results can be obtained from the Post processing part of ANSYS. The load-deflection and uplifts values at every step have been recorded.

\subsection{Validation of FE Results}

Experimental results [6] available for skew slab with skew angle $16.49^{\circ}$ are compared here with obtained FE results corresponding to skew slab with $16.49^{\circ}$ skew angle.

The load v/s deflection and load v/s uplift graphs comparing the experimental and finite element analysis results are presented in Chart -1 and Chart -2 respectively.

From Chart -1 and Chart -2, the FE model and Experimental results shows almost same results. The ultimate load and corresponding deflection for $\mathrm{FE}$ model are $27.6 \mathrm{kN}$ and $29.983 \mathrm{~mm}$ respectively whereas the ultimate load and corresponding deflection came from experimental result was $25 \mathrm{kN}$ and $29.3 \mathrm{~mm}$ respectively. When analyze these data, the FE results shows, the load is increased by $2.6 \mathrm{kN}$ and deflection is increased by $0.683 \mathrm{~mm}$. Maximum uplift obtained from experimental data was $1.65 \mathrm{~mm}$ whereas that for FE model was $1.324 \mathrm{~mm}$. Experimental data suggested that both LHS and RHS acute corners have same uplift but FE Model result suggested that up to ultimate load both acute corners have same uplift and after that they shows slight difference from each other. But from Chart -2 it is clear that, there is no noticeable change between LHS and RHS uplift values. So it can be concluded that FE model result shows good agreement with the experimental result.

\subsection{Load v/s Deflection Comparison}

From Chart -3 , it is observed that when skew angle increases from $0^{\circ}$ to $30^{\circ}$ the load carrying capacity of slab also increases. The ultimate load for $0^{\circ}, 16.49^{\circ}, 20^{\circ}$ and $30^{\circ}$ is $19.9 \mathrm{kN}, 27.6 \mathrm{kN}, 28.4 \mathrm{kN}$ and $34.5 \mathrm{kN}$ respectively. 
Skew angle $0^{\circ}$ indicates that the slab is rectangular in shape. It can be seen from the Chart -3 that the structure behaved linearly elastic up to the value of load $19.9 \mathrm{kN}$. The deflection corresponding to $19.9 \mathrm{kN}$ is $29.004 \mathrm{~mm}$. After $29.004 \mathrm{~mm}$ deflection started increasing without any significant decrement in load. The $40 \mathrm{~mm}$ deflection is reached with the load value of about $17.2 \mathrm{kN}$.

Considering graph corresponding to $16.49^{\circ}$ in Chart -3 , it can be seen that the structure behaved linearly elastic up to the value of load $27.6 \mathrm{kN}$. The deflection corresponding to
$27.6 \mathrm{kN}$ is $29.983 \mathrm{~mm}$. After $29.983 \mathrm{~mm}$ deflection, load started decreasing with increase in deflection. The $40 \mathrm{~mm}$ deflection is reached with the load value of about $24.2 \mathrm{kN}$.

For skew angle $20^{\circ}$, it can be seen that the structure behaved linearly elastic up to the value of load $28.4 \mathrm{kN}$. The deflection corresponding to $28.4 \mathrm{kN}$ is $29.011 \mathrm{~mm}$. After $29.011 \mathrm{~mm}$ deflection, load started decreasing with increase in deflection. The $40 \mathrm{~mm}$ deflection is reached with the load value of about $25.2 \mathrm{kN}$.

\section{Load Deflection Comparison Graph of Skew slab with $16.49^{\circ}$ Skew angle}

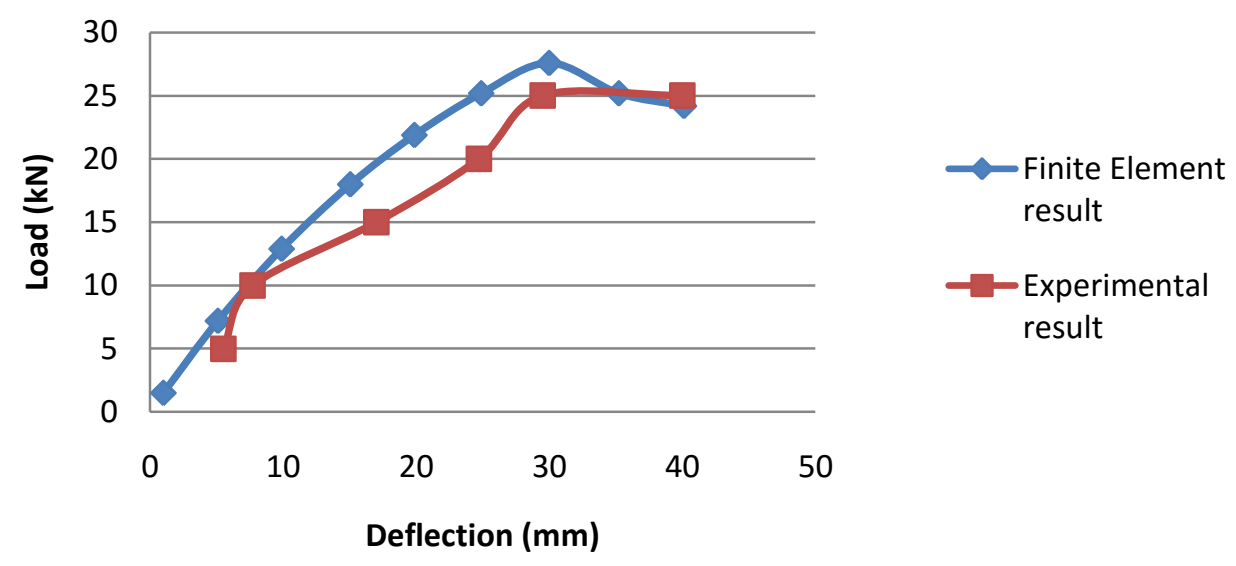

Chart -1: Load v/s Deflection Comparison Graph of Skew slab with $16.49^{\circ}$ skew

\section{Load v/s Uplift Comparison Graph of Skew slab with $16.49^{\circ}$ Skew angle}

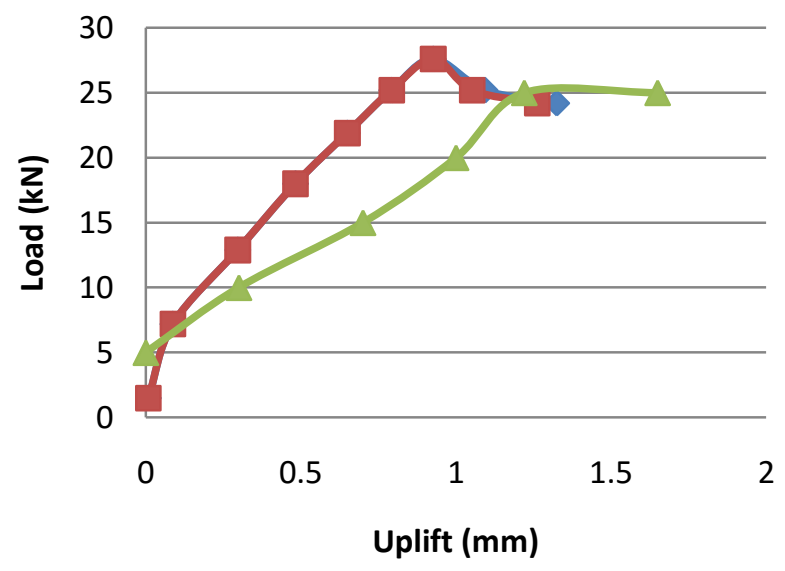

$\sim$ FE Model Uplift at LHS acute corner

-FE Model uplift at RHS acute corner

Experimental result

Chart -2: Load v/s Uplift Comparison Graph of Skew slab with $16.49^{\circ}$ skew 


\section{Load v/s Deflection Comparison Graph for Different Skew Angle}

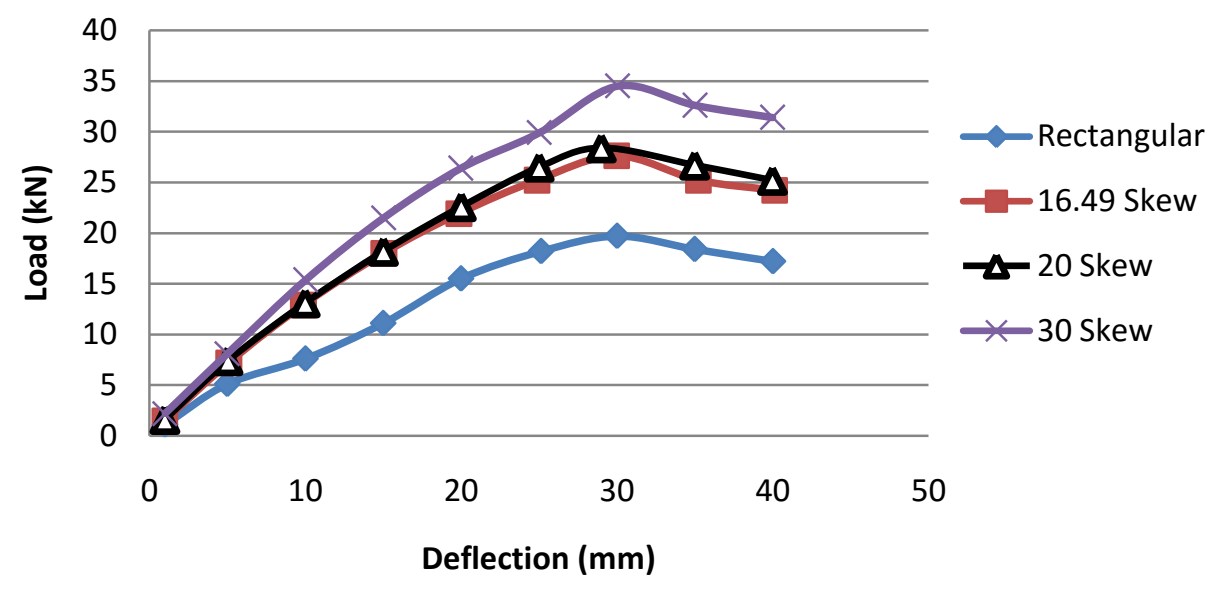

Chart -3: Load v/s Deflection Comparison Graph of Different Skew angle

For skew angle $30^{\circ}$, it can be seen that the structure behaved linearly elastic up to the value of load $34.5 \mathrm{kN}$. The deflection corresponding to $34.5 \mathrm{kN}$ is $30.045 \mathrm{~mm}$. After $30.045 \mathrm{~mm}$ deflection, load started decreasing with increase in deflection. The $40 \mathrm{~mm}$ deflection is reached with the load value of about $31.4 \mathrm{kN}$.

\subsection{Load v/s Uplift Comparison}

The graph representing load v/s uplift at LHS and RHS acute corners for skew angles $0^{\circ}, 16.49^{\circ}, 20^{\circ}$ and $30^{\circ}$ are shown in Chart -4 and Chart -5 respectively.

For $0^{\circ}$ skew angle, the maximum uplift occurred was $0.0131 \mathrm{~mm}$ in both the corners. This obtained value is very less compared to other skew angles. So the uplift at the corners for a rectangular slab is negligible.

\section{Load v/s Uplift(LHS) Comparison Graph for Different Skew Angle}

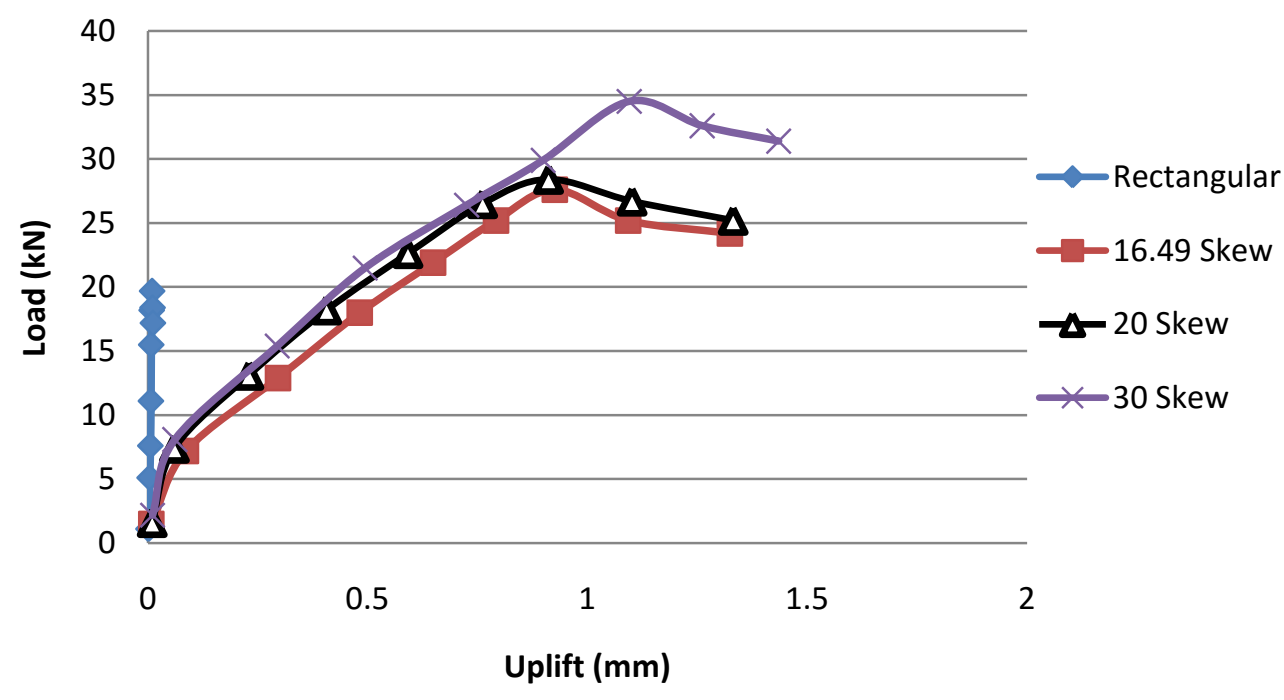

Chart -4: Load v/s Uplift (LHS) Comparison Graph of Different Skew angle 


\section{Load v/s Uplift(RHS) Comparison Graph for Different Skew Angle}

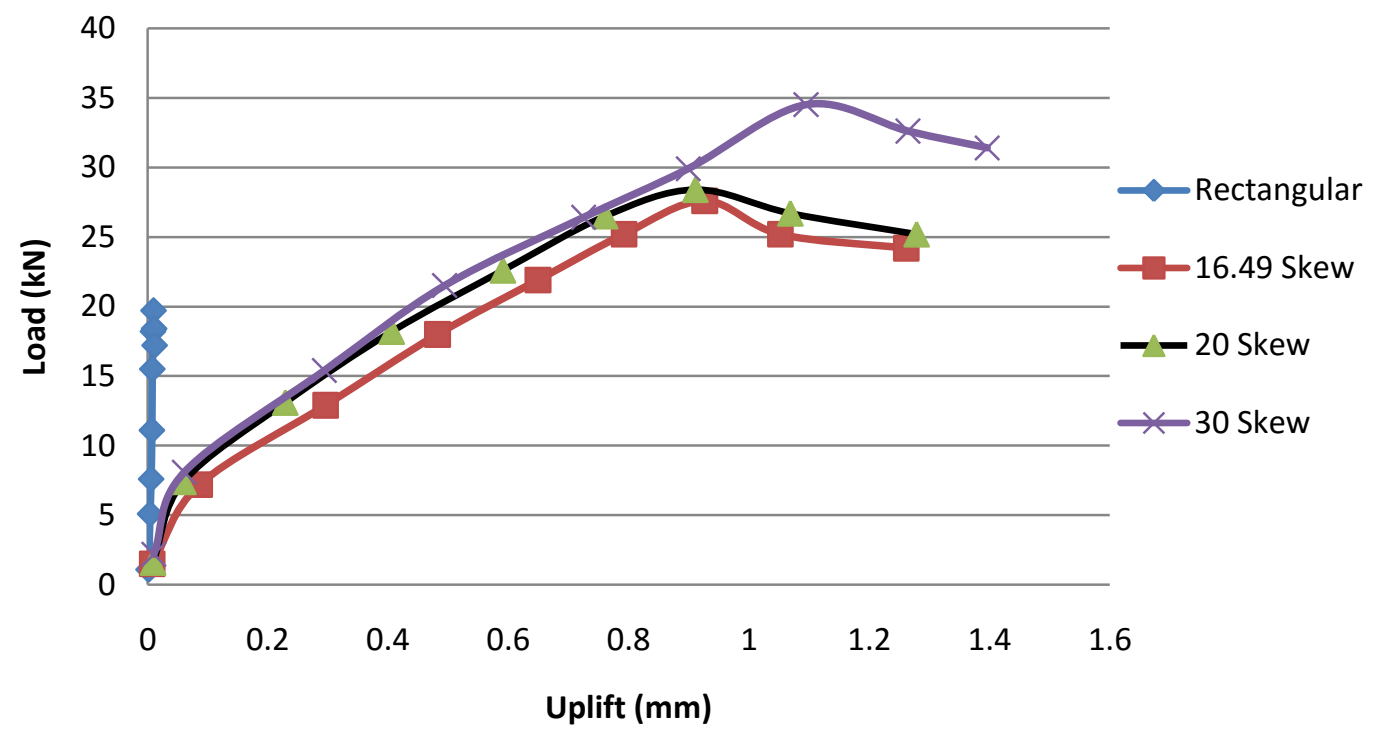

Chart -5: Load v/s Uplift (RHS) Comparison Graph of Different Skew angle

For $16.49^{\circ}$ skew angle, up to the ultimate load i.e. $27.6 \mathrm{kN}$, uplift at both LHS and RHS acute corners were same. After that they show slight difference from each other.

Up to the ultimate load i.e. $28.4 \mathrm{kN}$, uplift at both LHS and RHS acute corners were same for skew slab with $20^{\circ}$ skew angle. After that, uplift started increasing rapidly and both corners started to exhibit slight difference in uplift values.

For $30^{\circ}$ skew angle also, up to the ultimate load i.e. $34.5 \mathrm{kN}$, uplift at both LHS and RHS acute corners were same. After that they show slight difference from each other.

Here, all the slabs excluding rectangular slabs exhibits slight difference in uplift values after ultimate load. But this variation in uplift at both LHS and RHS acute corners are negligible.

From Chart -4 , it is observed that when skew angle increases from $0^{\circ}$ to $30^{\circ}$ the uplift at LHS acute corner also increases. The maximum uplift for $0^{\circ}, 16.49^{\circ}, 20^{\circ}$ and $30^{\circ}$ is $0.011 \mathrm{~mm}$, $1.324 \mathrm{~mm}, 1.331 \mathrm{~mm}$, and $1.435 \mathrm{~mm}$ respectively.

From Chart -5 , it is observed that when skew angle increases from $0^{\circ}$ to $30^{\circ}$ the uplift at RHS acute corner also increases. The maximum uplift for $0^{\circ}, 16.49^{\circ}, 20^{\circ}$ and $30^{\circ}$ is $0.011 \mathrm{~mm}$, $1.261 \mathrm{~mm}, 1.279 \mathrm{~mm}$, and $1.396 \mathrm{~mm}$ respectively.

\section{CONCLUSION}

The results of FE model of the skew slab with skew angle $16.49^{\circ}$ have found to be same as that of the experimental result. So it can be concluded that FE model results holds good with the experimental results.
The maximum deflection for skew slabs decreases with the increase in skew angle. This indicates that the load carrying capacity of skew slab increases with increase in skew angle. The uplift at acute corners of skew slab increases with increase in skew angle.

\section{REFERENCES}

[1] Mirzabozorg and Khaloo (2003) "Load Distribution Factors in Simply Supported Skew bridges." Journal of bridge engineering (C) ASCE, Vol. 8, Issue 4

[2] Huang, Shenton, and Chajes. s.l. (2004) "Load Distribution for a Highly Skewed Bridge" Journal of Bridge Engineering, Vol. 9, Issue 6

[3] James A.K. and Habib J.D. (2005), "Nonlinear FE analysis of $R C$ skewed slab bridges", Journal of structural engineering, Vol. 12, Issue 19, pp. 13381345

[4] Menassa, Mabsout, Tarhini and Frederick. (2007), "Influence of Skew Angle on Reinforced Concrete Slab Bridge.". : The Journal of Bridge Engineering, Vol.12, Issue 2.

[5] Misra, Trilok Gupta and Anurag. (2009) "Effect on support reactions of t-beam skew bridge decks." ARPN Journal of Engineering and Applied Sciences, Vols. Vol. 2, Issue 1

[6] Sharma M (2011) "Finite Element Modelling of Reinforced Concrete Skew Slab" ME (Structures) Thesis, Thapar University Patiala, Punjab.

[7] Dr. Ihsan A.S., Al-Shaarbaf, Munaf A.A., AlRmahee. (2009), "Nonlinear Finite Element Analysis of High Stregth Reinforced Concrete Slabs" AlQadisiya Journal For Engineering Sciences, Vol. 2, Issue 3 
[8] Das, D. , Sahoo, P. and Saha, K. (2010), “ $A$ variational analysis for large deflection of skew plates under uniformly distributed load through domain mapping technique", International Journal of Engineering, Science and Technology Vol. 1, Issue 1, pp. 16-32

[9] Ibrahim S. I. Harba. (2011), "Effect of Skew Angle on Behavior of Simply Supported RC T-beam bridge decks", ARPN Journal of Engineering and Applied Sciences, Vol. 6, Issue 8

[10] Vikash Khatri, Maiti P. R., Singh P. K. \& Ansuman Kar. (2012), "Study on Effect of Skew Angle in Skew Bridges" International Journal of Engineering Research and Development, Vol. 2, Issue 12, pp. 1318

[11] Sindhu B.V, Ashwin K.N, Dattatreya J.K. and S.V Dinesh. (2013), "Effect Of Skew Angle On Static Behaviour Of Reinforced Concrete Slab Bridge Decks", International Journal of Research in Engineering and Technology, Vol. 2, Issue 1, pp. 5058

[12] Arindam Dhar, Mithil Mazumder, Mandakini Chowdhury and Somnath Karmakar. (2013), "Effect of skew angle on longitudinal girder (support shear, moment, torsion) and deck slab of an IRC skew bridge”, The Indian Concrete Journal, pp 46-52

[13] Srinivasa C.V., Suresh Y.J. and Prema Kumar W.P. (2014), "Experimental And Finite Element Studies On Free Vibration Of Skew Plates", International Journal of Applied Mechanics and Engineering, vol.19, Issue 2, pp.365-377

[14] Abozaid L.A. Ahmed Hassan, Abouelezz A.Y. and L.M. Abdel-Hafez. (2014) "Nonlinear Behaviour of a Skew Slab Bridge under Traffic Loads" World Applied Sciences Journal Vol. 30, Issue 11, pp.14791493 